\title{
Effect of microencapsulated ferrous sulfate particle size on Cheddar cheese composition and quality
}

\author{
A. Arce and Z. Ustunol ${ }^{1}$ \\ Department of Food Science and Human Nutrition, Michigan State University, East Lansing 48824
}

\section{ABSTRACT}

Iron-fortified Cheddar cheese was manufactured with large microencapsulated ferrous sulfate (LMFS; 700$1,000 \mu \mathrm{m}$ in diameter) or small microencapsulated ferrous sulfate (SMFS; 220-422 $\mu \mathrm{m}$ in diameter). Cheeses were aged $90 \mathrm{~d}$. Compositional, chemical, and sensory characteristics were compared with control cheeses, which had no ferrous sulfate added. Compositional analysis included fat, protein, ash, moisture, as well as divalent cations iron, calcium, magnesium, and zinc. Thiobarbituric acid reactive species assay was conducted to determine lipid oxidation. A consumer panel consisting of 101 participants evaluated the cheeses for flavor, texture, appearance, and overall acceptability using a 9-point hedonic scale. Results showed $66.0 \%$ iron recovery for LMFS and $91.0 \%$ iron recovery for SMFS. Iron content was significantly increased from $0.030 \mathrm{mg}$ of $\mathrm{Fe} / \mathrm{g}$ in control cheeses to $0.134 \mathrm{mg}$ of $\mathrm{Fe} / \mathrm{g}$ of cheese for LMFS and $0.174 \mathrm{mg}$ of $\mathrm{Fe} / \mathrm{g}$ of cheese for SMFS. Fat, protein, ash, moisture, magnesium, zinc, and calcium contents were not significantly different when comparing iron-fortified cheeses with the control. Iron fortification did not increase lipid oxidation; however, iron fortification negatively affected Cheddar cheese sensory attributes, particularly the LMFS fortified cheese. Microencapsulation of ferrous sulfate failed to mask iron's distinct taste, color, and odor. Overall, SMFS showed better results compared with LMFS for iron retention and sensory evaluation in Cheddar cheese. Results of this study show that size of the microencapsulated particle is important in the retention of the iron in the cheese and its sensory attributes. This study provides new information on the importance of particle size with microencapsulated nutrients.

Key words: Cheddar cheese, microencapsulation, iron fortification, sensory, lipid oxidation

Received October 6, 2017.

Accepted March 22, 2018

${ }^{1}$ Corresponding author: ustunol@anr.msu.edu

\section{INTRODUCTION}

Globally, iron, iodine, folate, vitamin A, and zinc are the most deficient micronutrients in the diet (Bailey et al., 2015). The most susceptible populations for micronutrient deficiencies are children and pregnant women (Fulgoni et al., 2011; Keast et al., 2013; Malpeli et al., 2013). The World Health Organization (WHO, 2016) reported that one-third of the world's population, 2 billion people, suffers some level of iron deficiency. Iron plays an important role in the functionality of the hemoglobin protein, part of the red blood cell, which is responsible for carrying oxygen throughout the body (Sadava et al., 2008). Anemia, premature births, maternal and fetal death, low immunological competency, and impaired psychomotor development are some of the consequences of consistent low iron intake and absorption (Cherayil, 2010; Georgieff, 2011).

The 2 most widely used approaches to fighting malnutrition, including iron deficiency, are food fortification and micronutrient supplementation (Allen et al., 2006). Currently food fortification is the most promising and cost-effective strategy to reduce malnutrition on a global scale (Horton et al., 2008; Fiedler and Macdonald, 2009). Due to its popularity, cheese can be the perfect vehicle for iron-fortification programs. In the United States, the majority of milk is consumed as cheese, fluid milk, ice cream, yogurt, and as other dairy products (IDFA, 2016). In 2013, per capita consumption of natural cheeses was $15.3 \mathrm{~kg}$ (IDFA, 2016). Milk and cheese are nutrient-dense foods; cheese is often the recommended meat alternative in school lunch programs and in vegetarian diets. However, milk, cheese, and other dairy products are naturally low in iron; one serving ( $28 \mathrm{~g}$ ) of Cheddar cheese provides approximately $0.04 \mathrm{mg}$ of iron (USDA National Nutrient Database for Standard Reference, 2016).

Iron is a challenging micronutrient to add to foods due to its potential to negatively affect the organoleptic properties (Allen et al., 2006). Recently, microencapsulated iron compounds have received attention because of their potential to increase iron bioavailability and to reduce sensory changes in foods (Dubey et al., 2009; 
Frankel 2014). Zhang and Mahoney (1989, 1990), pioneers in dairy fortification studies using iron, fortified Cheddar cheese with different iron compounds and reported that it is possible to produce good-quality iron-fortified Cheddar cheese; however, the iron fortificants that produced good-quality cheese have limited bioavailability (Allen et al., 2006). Rice and McMahon (1998) fortified Mozzarella cheese with casein-bound iron, whey protein-chelated iron, or $\mathrm{FeCl}_{3}$-iron complex compounds. Although a trained sensory panel detected slight increase in metallic, oxidized, and off flavors compared with control cheeses, these differences were not statistically significant; those authors did not report on the bioavailability of the iron compounds used. Motzok et al. (1975) reported that bioavailability of reduced iron is affected by particle size. Boccio et al. (1997) reported higher bioavailability for encapsulated ferrous sulfate compared with nonencapsulated iron compounds in fluid milk studies, but no overall product acceptability or its sensory characteristics were reported. Wegmüller et al. (2004) found that reducing particle size of microencapsulated ferric pyrophosphate, from 21 to $0.5 \mu \mathrm{m}$, increased bioavailability by $50 \%$, leading to search for ideal particle size for optimal absorption and bioavailability.

Iron can further be a challenging nutrient to add to milk and dairy foods due to its potential to displace other divalent cations in the milk system (Vasudevan et al., 2002). Milk minerals have an important role in cheesemaking, such as coagulation, whey draining, and curd texture (Patiño et al., 2005). Gonzalez-Martin et al. (2009) reported that mineral profile in cheese played a key role in cheese yield and ripening time. Minerals such as calcium, for example, are in a delicate equilibrium between the colloidal calcium phosphate associated with the casein micelles and soluble calcium phosphate found in water phase. Displacement of calcium with another divalent cation can shift the calcium equilibrium moving the colloidal calcium to soluble phase. Kahraman and Ustunol (2012) suggested that when Cheddar cheese is fortified with zinc sulfate there is displacement of calcium with zinc at the casein micelle level due to loss of calcium in the whey with an increase in zinc concentration in the fortified cheese. The major milk protein caseins have strong affinity to divalent cations; however, binding affinity depends on different factors including $\mathrm{pH}$, ionic strength, temperature, and phosphate group content (On-Nom et al., 2010).

The goal of fortification is to increase nutritional content in a food without compromising other nutrients. If any mineral displacements occur in cheese, the displaced divalent cation (i.e., calcium, magnesium, or zinc; nutritionally important and present in significant amounts in cheese) will be lost during the whey-draining and cheese-pressing steps. Currently, limited literature is available on divalent cation balance disturbances when fortifying cheese with minerals such as iron.

We hypothesized that fortification of Cheddar cheese with microencapsulated ferrous sulfate would increase iron content with no major compositional changes. Additionally, reducing microencapsulated ferrous sulfate particle size would increase iron retention and reduce the effect on sensory attributes. Thus, the objectives of our study were to evaluate the effect of microencapsulated ferrous sulfate with large and small particle sizes on Cheddar cheese quality, and to assess composition, lipid oxidation, and sensory differences. Divalent cation balance disturbances when fortifying Cheddar cheese with iron was also evaluated.

\section{MATERIALS AND METHODS}

\section{Microencapsulated Ferrous Sulfate Salts}

Microencapsulated ferrous sulfate with diameters of 700 to 1,000 and 220 to $422 \mu \mathrm{m}$ per particle [large (LMFS) and small (SMFS), respectively] were obtained from Paul Lohmann Inc. (Emmerthal, Germany). Both iron salts were microencapsulated with 1 layer of hydrogenated palm oil. Iron salts were sterilize based on the current good manufacturing processes, pharmacopoeia, and international food regulations followed by the manufacturer. This was verified in our laboratory by standard microbial plate counts.

For the cheese-fortification dosage, $30 \%(4.5 \mathrm{mg})$ of the iron recommended daily allowance (RDA) per serving was selected, assuming an average RDA of 15 $\mathrm{mg}$ of $\mathrm{Fe} / \mathrm{d}$ in the United States. Table 1 shows the amount of iron salt added to Cheddar cheese based on the iron content of each fortificant.

Table 1. Ferrous sulfate treatments and fortification dosage

\begin{tabular}{llccc}
\hline Treatment & $\mathrm{Fe}^{2+}$ Source & Diameter, $\mu \mathrm{m}$ & $\mathrm{Fe}^{2+}$ content, \%, wt/wt $^{\text {Fortification dosage }}$ \\
\hline Control & - & - & - & 16.8 \\
LMFS & Large microencapsulated ferrous sulfate & $700-1,000$ & 9.0 & - \\
SMFS & Small microencapsulated ferrous sulfate & $220-422$ & 0.95 \\
\hline
\end{tabular}

${ }^{1}$ Grams of microencapsulated ferrous sulfate/ $\mathrm{kg}$ of Cheddar cheese. 


\section{Cheddar Cheese Manufacturing}

Cheddar cheese was manufactured at the Michigan State University Dairy Plant using standard cheese manufacturing procedures. Whole milk (Michigan Milk Producers Association, Novi, MI) with a $3.41 \%$ fat, $3.02 \%$ protein, and $8.83 \%$ SNF composition was HTST pasteurized $\left(72^{\circ} \mathrm{C}, 15 \mathrm{~s}\right)$. Whole milk $(190 \mathrm{~L})$ was equally distributed to 3 cheese vats, to which $1 \%$ wt/wt Cheddar cheese starter culture (DVS 98, CHR Hansen, Hørsholm, Denmark) was added with constant stirring. Milk was incubated for at $32^{\circ} \mathrm{C}$ for $30 \mathrm{~min}$ followed by addition of $6 \mathrm{~mL}$ of annatto and $13 \mathrm{~mL}$ of rennet (diluted $40 \times$ in distilled water; Chy-Max, Chr. Hansen) per vat. Milk was allow to coagulate for 30 min at $32^{\circ} \mathrm{C}$. Using wire knives, milk curd was cut when adequate firmness was reached. After cutting, curd was healed for $30 \mathrm{~min}$ at $35^{\circ} \mathrm{C}$. Then, curd was cooked at $38^{\circ} \mathrm{C}$ for $1 \mathrm{~h}$. Whey was drained after the cooking step and the resulting cheese curds were matted and cut into rectangular blocks to then be flipped every $15 \mathrm{~min}$ at $35^{\circ} \mathrm{C}$ (cheddaring process). The process was stopped when titratable acidity reached $0.62 \%$ and then curd blocks were milled by hand. The cheese was weighted and equally divided among 3 containers for the salting step.

The microencapsulated iron salts were incorporated during the salting step of Cheddar cheese manufacturing. Commercial table salt $(0.25 \% \mathrm{wt} / \mathrm{wt}$ of cheese curd) and microencapsulated iron treatments (amounts as indicated in Table 1) were mixed for $10 \mathrm{~min}$ in plastic bags before incorporation into cheese curds. Salted Cheddar cheese curds were transferred to cheese hoops and pressed at $276 \mathrm{kPa}$ for $12 \mathrm{~h}$. Pressed Cheddar cheese was vacuum-sealed in plastic bags and ripened stored at $8^{\circ} \mathrm{C}$ for $90 \mathrm{~d}$ in a cooler with limited light exposure. Cheddar cheesemaking was replicated 2 additional times using the same milk source.

\section{Proximate Analysis}

All cheeses manufactured were analyzed for protein, fat, moisture, and ash content. Moisture and ash were determined using AOAC standards methods (AOAC International, 2000). Fat content was determined according to the Babcock method (Kahraman and Ustunol, 2012), and protein content was determined by the Kjeldahl method (Certified Laboratories Inc., Plainview, NJ).

\section{Mineral Analysis}

All cheeses manufactured were also analyzed for divalent cations, iron, calcium, zinc, and magnesium using a
55B AA Atomic Absorption Spectrophotometer (AAS; Agilent Technologies Co., Santa Clara, CA). The AAS was calibrated using standard solutions and by establishing a standard curve. Cheddar cheese $(1.0 \mathrm{~g})$ was dissolved in concentrated nitric acid $(8 \mathrm{~mL})$ for $2 \mathrm{~h}$ in pressure tubes (predigestion treatment). Samples were transferred to a Multiwave 3000 Modular microwave system (Anton Paar, Graz, Austria) and digested at $600 \mathrm{~W}, 160^{\circ} \mathrm{C}, 1,300 \mathrm{kPa}$, with 30 min ramp time and $10 \mathrm{~min}$ holding time. After microwave digestion, $2 \mathrm{~mL}$ of $30 \%$ hydrogen peroxide (General Industrial Chemicals, East Hanover, NJ) was added to each sample and the final volume was adjusted to $25 \mathrm{~mL}$ using distilled water. Approximately 5 -mL aliquots were separated for calcium content. The remaining $20 \mathrm{~mL}$ of solution was analyzed for iron, magnesium, and zinc. For calcium analysis, $3 \mathrm{~mL}$ of the digested cheese was diluted to 25 $\mathrm{mL}$ by adding $3 \mathrm{~mL}$ of lanthanum solution $(1,000 \mu \mathrm{g} /$ $\mathrm{mL}$ ) and distilled water. The resulting solution was further diluted by taking a $0.702-\mathrm{mL}$ aliquot and adjusting its final volume to $20 \mathrm{~mL}$ using distilled water. The final solution was used for calcium content determination. To assess the accuracy and precision of the AAS, a standard material (0.5 g of bovine liver; Standard Reference Material 1577b) from the National Institute of Standards and Technology (Gaithersburg, MD) was analyzed along with Cheddar cheese. In addition to the cheese, whey from each treatment was also collected during Cheddar cheese manufacturing. Whey samples were analyzed for iron content. Cheddar cheese whey $(5.0 \mathrm{~g})$ dissolved in concentrated nitric acid $(10 \mathrm{~mL})$ was predigested, digested, and diluted the same way as Cheddar cheese for iron AAS analysis. Each analysis was done in duplicates for all 3 replicates.

\section{Determination of Lipid Oxidation}

The thiobarbituric acid (TBA) assessment was selected to measure lipid oxidation in Cheddar cheese. The TBA relies on the formation of malondialdehyde (MDA), a secondary product of lipid oxidation. According to this method, $1 \mathrm{~mol}$ of MDA reacts with 2 mol of TBA, giving a pink product in solution that can be quantified using a spectrophotometer. Due to instability of MDA, 1,1,3,3-tetraethhoxypropane (TEP), a MDA precursor, was used instead in TBA analysis.

Cheddar cheese samples $(5.0 \pm 0.01 \mathrm{~g})$ were placed in a beaker and $1.0 \mathrm{~mL}(0.2 \mathrm{mg} / \mathrm{mL})$ of butylated hydroxytoluene (Sigma-Aldrich, St. Louis, MO) was added to stop oxidation. For every cheese sample measured, a spiked sample (12 mL of $10 \mu M$ TEP; Sigma-Aldrich) was prepared to correct for any variation that may have occurred during lipid extraction. Cheese samples were blended with either 33.5 (unspiked) or $45.5 \mathrm{~mL}$ (spiked) 
$10 \%$ TCA (Sigma-Aldrich) in $0.2 \mathrm{M} \mathrm{H}_{3} \mathrm{PO}_{4}$ (wt/vol; Sigma-Aldrich). The mixture was filtered through Whatman No. 1 filter paper, and $5 \mathrm{~mL}$ of the filtrate was added to $5 \mathrm{~mL} 0.02 M$ TBA (Sigma-Aldrich) to reach a final volume of $10 \mathrm{~mL}$. Filtrate-TBA solutions were incubated in boiling water for $30 \mathrm{~min}$ and absorbance readings were recorded at $530 \mathrm{~nm}$ using a spectrophotometer (Genesys 20 Spectrophotometer, Thermo Fisher Scientific, Waltham, MA). The thiobarbituric acid reactive species (TBARS) were calculated from the standard curve prepared with $0,1.25,2.50$, $3.75,5.00$, and $10.00 \mathrm{nmol} / \mathrm{mL}$ of TEP.

\section{Sensory Evaluation by Consumer Panel}

After $90 \mathrm{~d}$ of aging, iron-fortified Cheddar cheeses were analyzed for acceptability. A consumer panel (n $=101$ ) familiar with Cheddar cheese was recruited at Michigan State University. The sensory evaluation was performed in the Food Science Sensory Laboratory (Michigan State University). The laboratory had 8 individual computer booths with control lighting and temperature. Participants received a brief explanation of the study and signed a consent form for the University Committee on Research Involving Human Subjects at Michigan State University. Samples (20 g, $5^{\circ} \mathrm{C}$ ) were placed in clear plastic cups labeled with a random 3-digit code and the order of the presentation was randomized. Water and unsalted crackers were provided to the panelists for palate cleansing. Panelists were asked to rate appearance, texture, flavor, and overall acceptability using 9-point hedonic scale, where $1=$ dislike extremely, $5=$ neither like nor dislike, and $9=$ like extremely. Following numerical scoring, participants were asked to select the best texture attributes for the samples from a given list (firm, soft, very hard, grainy, rubbery, crumbly, runny, dry, and chewy or none). Following flavor rating, participants were asked to select the best flavor attributes for the samples from a given list (sour-acidic, vinegary, greasy, sweet, metallic, buttery, salty, moldy, spicy, other, or none). Texture and flavor attribute list were selected based on common Cheddar cheese attributes and the purpose of this study.

\section{Statistical Analysis}

Cheese manufacturing was replicated 3 times in a completely randomized design. TBA analysis, compositional and divalent cation determinations were performed in duplicates and analyzed using SAS software version 9.4 (SAS Institute Inc., Cary, NC). One-way ANOVA $(P=0.05)$ and Tukey's honestly significant difference (HSD) test were performed to determine statistical difference between the treatments and the control. Data from the consumer panel was collected using SIMS software (SIMS, Berkley Heights, NJ) and analyzed using SAS software version 6.0 by 1 -way ANOVA and Tukey's HSD test.

\section{RESULTS AND DISCUSSION}

Several studies have reported on iron fortification of cheeses (Zhang and Mahoney, 1989, 1990, 1991; Rice and McMahon, 1998); however, as far as we know, our study is the first to investigate microencapsulated iron and the effect of microencapsulation particle size on iron retention in the cheese and on cheese composition and quality. We focused on the effect of particle size on iron retention, effect on cheese composition, particularly its effect on other significant minerals in the cheese, and cheese quality.

\section{Compositional Analysis}

The effect of microencapsulated ferrous sulfate on Cheddar cheese composition is reported in Table 2 . Although not statistically different $(P>0.5)$, ash content was slightly higher for iron-fortified cheeses, as expected. The SMFS-fortified cheese had slightly higher ash content than the LMSF-fortified cheese, suggesting that smaller particle size of microencapsulated iron was more effective than larger particle size in the incorporation of iron into Cheddar cheese. Iron content of the SMFS-fortified cheese was 6 times higher than the control cheeses compared with LMFS-fortified cheese, which was 4 times higher than the control cheese. This confirmed that smaller particle microencapsulated iron was more effective in being incorporated in to the cheese (Table 3). In SMFS-fortified cheese, approximately $91 \%$ of the added iron was recovered in the cheese, whereas in LMFS-fortified cheese approximately $66 \%$ of the iron was recovered (Table 3). These results were consistent with the iron lost into the whey released during pressing of the curd (Table 3). Iron fortification did not have a significant effect on fat, protein, and moisture content of the cheeses (Table 2). In previous studies, iron recoveries in Cheddar cheese were reported to be 71 to $81 \%$ for $\mathrm{FeCl}_{3}, 52$ to $53 \%$ for ferric citrate, 55 to $75 \%$ for Fecasein complex, and 70 to $75 \%$ for ferripolyphosphatewhey protein complex (Zhang and Mahoney, 1989).

Milk is relatively poor in iron, and the majority of the iron present is bound to milk proteins such as caseins. Iron binding to caseins may be due primarily to interactions with AA such as Asp, Glu, and phosphoserine, which are present in caseins; thus, availability of these groups to interact with iron is important. The distribution and ionization status of iron, however, are 
Table 2. Proximate analysis of Cheddar cheese fortified with microencapsulated ferrous sulfate ${ }^{1}$

\begin{tabular}{lcccc}
\hline Treatment & Fat & Protein & Ash & Moisture \\
\hline Control & $32.4 \pm 0.5^{\mathrm{a}}$ & $24.08 \pm 0.15^{\mathrm{a}}$ & $3.77 \pm 0.19^{\mathrm{a}}$ & $36.86 \pm 1.45^{\mathrm{a}}$ \\
LMFS & $32.4 \pm 0.2^{\mathrm{a}}$ & $24.66 \pm 0.68^{\mathrm{a}}$ & $3.81 \pm 0.06^{\mathrm{a}}$ & $36.89 \pm 0.56^{\mathrm{a}}$ \\
SMFS & $32.6 \pm 0.1^{\mathrm{a}}$ & $23.63 \pm 0.17^{\mathrm{a}}$ & $3.99 \pm 0.18^{\mathrm{a}}$ & $36.52 \pm 0.16^{\mathrm{a}}$ \\
\hline & ${ }^{\mathrm{a}}$ Means within a column with different superscripts are significantly different $(P<0.05) ; \mathrm{n}=3$. \\
\multicolumn{1}{l}{ LMFS = large microencapsulated ferrous sulfate $(0.95 \mathrm{~g} / \mathrm{kg} ; 700-1,000 \mu \mathrm{m})$, SMFS $=$ small microencapsu- } \\
\multicolumn{2}{l}{ lated ferrous sulfate $(1.78 \mathrm{~g} / \mathrm{kg} ; 220-420 \mu \mathrm{m})}$.
\end{tabular}

affected by AA phosphorylation, $\mathrm{pH}$, and other factors (West, 1986; Peres et al., 1999; Raouche et al., 2009; Sugiarto et al., 2010). A small amount, about $14 \%$ of the iron is reported to be associated with the milkfat, specifically with the milkfat globule membrane (Flyn and Cashman, 1997). The successful incorporation of iron into Cheddar cheese in our study may have been due to casein-iron interactions; however, all things being equal, SMFS was better incorporated into Cheddar cheese than LMFS. This was probably due to the better entrapment of a smaller particles into the cheese curd compared with a larger size, where particles are more readily lost in the whey. In addition, the lipophilic coating material of the smaller microencapsulated particles may have better interacted with the fat phase of the cheese due to increased surface area by the size reduction, making them being better at mimicking fat. To the best of our knowledge, no reports have been published supporting the effect of particle size differences in incorporation of micronutrients into foods. However, Wegmüller et al. (2004) reported that reducing particle size of microencapsulated ferric pyrophosphate from 21 to $0.5 \mu \mathrm{m}$ significantly increased bioavailability in iron assessment studies, but they did not report on the effectiveness of its incorporation into foods.

Gulbas and Saldami (2005) and Kahraman and Ustunol (2012) suggested that fortification of cheese with divalent cations might displace other key divalent cations that have less affinity to caseins; for individual cations, affinity with caseins is $\mathrm{Fe}^{2+}>\mathrm{Zn}^{2+}>\mathrm{Ca}^{2+}>\mathrm{Cu}^{2+}>$ $\mathrm{Mg}^{2+}$ (Philippe et al., 2005). However, this binding affinity is dependent on $\mathrm{pH}$, ionic strength, temperature, and availability of phosphate groups (On-Nom et al. 2010). Based on these reports, we further investigated if iron displaced zinc, calcium, and magnesium, 3 key divalent minerals in cheese. Our results showed that calcium, magnesium, and zinc levels were not affected by iron fortification. Their levels in iron-fortified cheeses were similar compared with the control cheeses (Figure 1). This is very significant in that the point of addition of the fortificant nutrient during the cheesemaking process may affect the mineral balance in the milk system and displacement of other minerals. Kahraman and Ustunol (2012) added zinc sulfate to the cheese milk, and during the incubation period milk may have had the opportunity to reestablish the mineral equilibrium between the colloidal casein and the serum phases. In the present study, the microencapsulated iron was added to the cheese curd during the salting step. At this stage, the cheese matrix had already formed and cheese whey drained, thereby not allowing for the reestablishment of the mineral equilibrium.

\section{TBA}

Iron is a known pro-oxidant; it induces lipid oxidation and produces negative organoleptic changes when added to fat containing foods. Lipid oxidation is further enhanced in foods by heat and presence of light. Lipid oxidation results in the formation of peroxides, aldehydes, epoxides, ketone, and alcohol groups associated with rancid and off-flavors (Frankel, 2014). Formation of off-flavors in iron fortified dairy foods has been reported previously (Zhang and Mahoney, 1991;

Table 3. Total iron content of cheeses manufactured, iron content of corresponding whey $(\mathrm{mg} / \mathrm{g})$ and percent recovery during the fortification of Cheddar cheese with microencapsulated ferrous sulfate

\begin{tabular}{lccc}
\hline Treatment & Iron in cheese & Iron in whey & \% Recovery $^{2}$ \\
\hline Control & $2.96 \times 10^{-2} \pm 5.7 \times 10^{-4 \mathrm{a}}$ & $4.49 \times 10^{-4} \pm 4.0 \times 10^{-4 \mathrm{a}}$ & N/A \\
LMFS & $13.43 \times 10^{-2} \pm 1.40 \times 10^{-2 \mathrm{~b}}$ & $8.83 \times 10^{-4} \pm 2.9 \times 10^{-4 \mathrm{a}}$ & $66.0^{\mathrm{a}}$ \\
SMFS & $17.41 \times 10^{-2} \pm 2.1 \times 10^{-3 \mathrm{c}}$ & $2.31 \times 10^{-3} \pm 2.0 \times 10^{-3 \mathrm{a}}$ & $91.0^{\mathrm{b}}$ \\
\hline
\end{tabular}

${ }^{\mathrm{a}-\mathrm{c}}$ Means within a column with different superscripts are significantly different. $(P<0.05) ; \mathrm{n}=3$.

${ }^{1}$ LMFS $=$ large microencapsulated ferrous sulfate $(0.95 \mathrm{~g} / \mathrm{kg} ; 700-1,000 \mu \mathrm{m})$, SMFS $=$ small microencapsulated ferrous sulfate $(1.78 \mathrm{~g} / \mathrm{kg} ; 220-420 \mu \mathrm{m})$.

${ }^{2}$ Percent recovery $=($ Fe in Fe treatments $-\mathrm{Fe}$ in control/fortification level $) \times 100 . \mathrm{N} / \mathrm{A}=$ not applicable. 
Table 4. Effect of microencapsulated ferrous sulfate on lipid oxidation of Cheddar cheese (expressed as thiobarbituric acid reactive species, $\mathrm{mg} / \mathrm{kg}$ of malondialdehyde) ${ }^{1}$

\begin{tabular}{lccc}
\hline $\begin{array}{l}\text { Ripening } \\
\text { time, }\end{array}$ & Control & LMFS & SMFS \\
\hline 0 & $0.50 \pm 0.05^{\mathrm{a}}$ & $0.54 \pm 0.12^{\mathrm{a}}$ & $0.58 \pm 0.19^{\mathrm{a}}$ \\
10 & $0.43 \pm 0.29^{\mathrm{a}}$ & $0.58 \pm 0.40^{\mathrm{a}}$ & $0.69 \pm 0.26^{\mathrm{a}}$ \\
20 & $0.38 \pm 0.33^{\mathrm{a}}$ & $0.53 \pm 0.33^{\mathrm{a}}$ & $0.42 \pm 0.11^{\mathrm{a}}$ \\
30 & $0.30 \pm 0.29^{\mathrm{a}}$ & $0.35 \pm 0.21^{\mathrm{a}}$ & $0.40 \pm 0.17^{\mathrm{a}}$ \\
60 & $1.77 \pm 2.71^{\mathrm{a}}$ & $0.62 \pm 0.47^{\mathrm{a}}$ & $0.54 \pm 0.14^{\mathrm{a}}$ \\
90 & $0.47 \pm 0.43^{\mathrm{a}}$ & $0.64 \pm 0.46^{\mathrm{a}}$ & $0.62 \pm 0.14^{\mathrm{a}}$ \\
\hline
\end{tabular}

${ }^{\mathrm{a}}$ Means within a row with different superscripts are significantly different $(P<0.05) ; \mathrm{n}=3$.

${ }^{1}$ LMFS $=$ large microencapsulated ferrous sulfate $(0.95 \mathrm{~g} / \mathrm{kg} ; 700-$ $1,000 \mu \mathrm{m})$, SMFS $=$ small microencapsulated ferrous sulfate $(1.78 \mathrm{~g} /$ $\mathrm{kg} ; 220-420 \mu \mathrm{m})$.

Prom-u-thai et al., 2009; Kiskini et al., 2012); however, we anticipated that microencapsulation of iron may provide protection from lipid oxidation in our study.

Table 4 shows TBA values (TBARS) for LMFS- and SMFS-fortified Cheddar cheese compared with the control cheese during 90-d aging period. The TBARS were not significantly different among iron-fortified cheeses and the control cheese throughout the 90 -d aging period, thus suggesting that iron fortification did not contribute to enhanced lipid oxidation of the cheeses. However, it is possible microencapsulation provided protection against lipid oxidation; this will need to be confirmed in a study with an unencapsulated iron-fortified cheese as control.

Zhang and Mahoney (1989) reported that although TBA numbers slightly increased in Cheddar cheese fortified with $\mathrm{FeCl}_{3}$, ferric citrate, Fe-casein complex, and ferripolyphosphate-whey protein complex, they were within the range of reported by others for unfortified cheeses. Those authors also reported slightly higher TBA numbers in processed cheese fortified with iron. Similar results were reported by Rice and McMahon (1998) in Mozzarella cheese; they indicated that binding of iron by the milk proteins would reduce the ability of iron to participate in iron catalyzed production of hydroxyl radicals and lipid peroxidation by restricting change in the oxidation state between $\mathrm{Fe}^{2+}$ and $\mathrm{Fe}^{3+}$. This may have been the case in our study as well, in addition to the protection provided by the microencapsulation of the iron. Kwak et al. (2003) showed lower TBA values in Cheddar cheese fortified with microencapsulated ferric ammonium sulfate iron compared with the control.
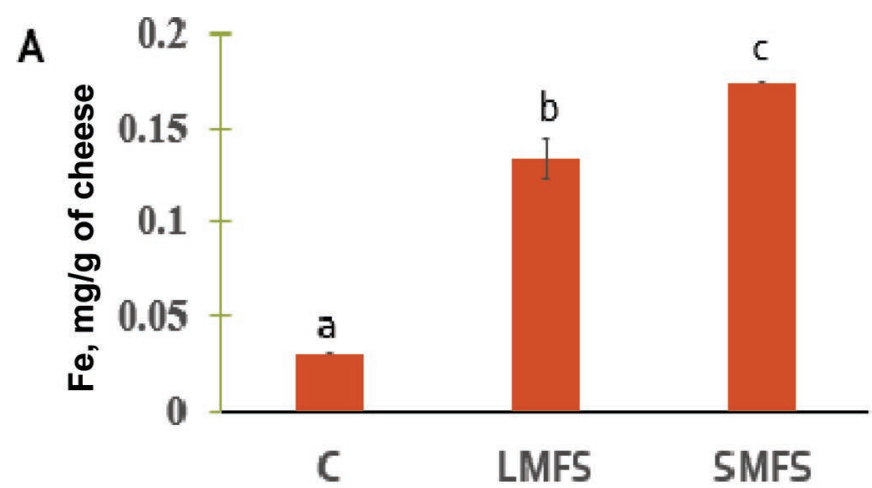

C

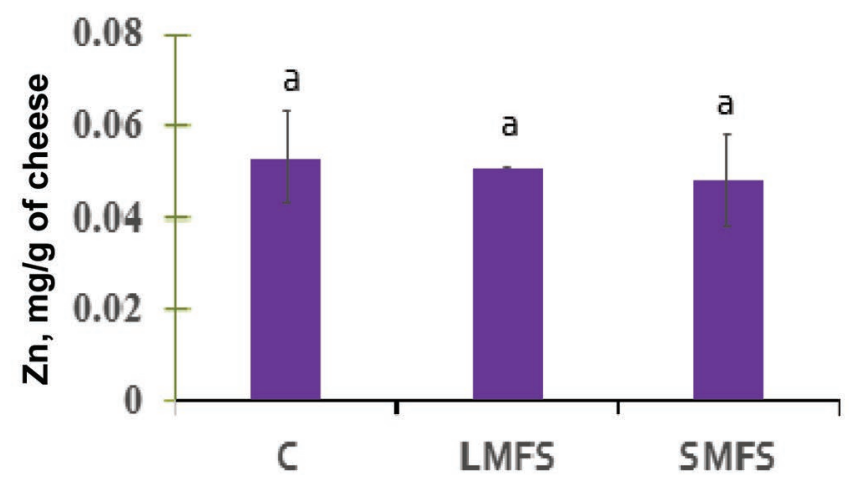

B

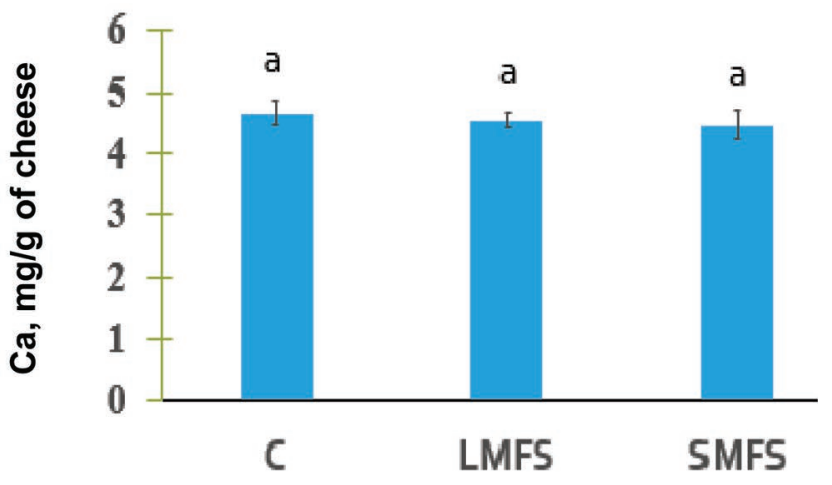

D

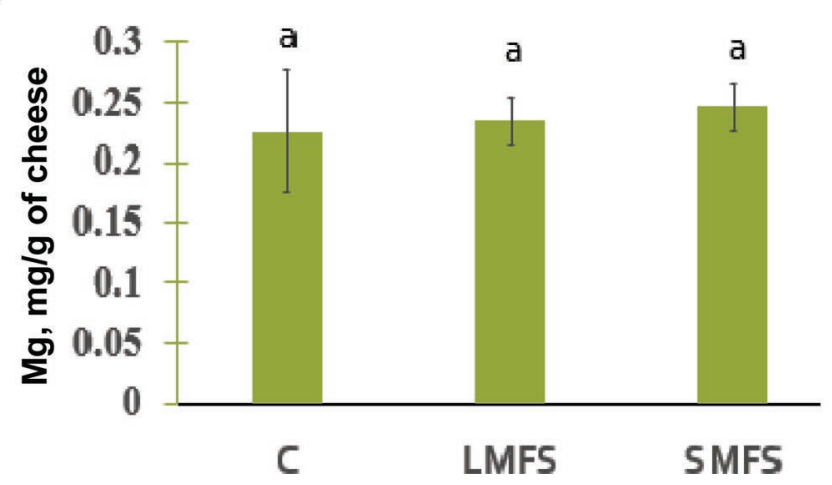

Figure 1. Mineral content of Cheddar cheese fortified with microencapsulated ferrous sulfate: $\mathrm{A}=$ iron, $\mathrm{B}=$ calcium, $\mathrm{C}=$ zinc, and $\mathrm{D}=$ magnesium. $\mathrm{C}=$ control; LMFS = large microencapsulated ferrous sulfate $(0.95 \mathrm{~g} / \mathrm{kg} ; 700-1,000 \mu \mathrm{m})$; SMFS $=$ small microencapsulated ferrous sulfate $(1.78 \mathrm{~g} / \mathrm{kg} ; 220-420 \mu \mathrm{m})$. Means within a column with different letters $(\mathrm{a}-\mathrm{c})$ are significantly different $(P<0.05) ; \mathrm{n}=3$. Error bars represent SD. Color version available online. 
Although some correlation exists between TBARS and sensory scores (Mehta et al., 2015), because we used a consumer panel rather than a trained panel we did not specifically ask the panelist to score the cheeses for oxidized flavors but rather for quality attributes.

\section{Sensory Evaluation}

Consumer panelists $(\mathrm{n}=101)$ scored control cheeses significantly higher $(P<0.05)$ in appearance, texture, flavor, and overall acceptability. Both iron-fortified cheeses were scored lower $(P<0.05)$ than the control cheeses. (Table 5). Appearance and texture scores were significantly higher $(P<0.05)$ for the control cheese when compared with LMFS- and SMFS-fortified cheeses. For flavor and overall acceptability, all treatments were significantly different $(P<0.05)$; the control had the highest score and LMFS-fortified cheese had the lowest score. The main reason for selecting microencapsulated ferrous sulfate as the fortificant in this study was its low potential to affect Cheddar cheese quality. One of the advantages of using microencapsulated salts is to prevent lipid oxidation reactions and to mask iron's distinct flavor and odors (Paul Lohmann Inc.). Although, lipid oxidation was not enhanced due to iron fortification in our study, panelists consistently scored LMFS- and SMFS-fortified cheeses lower than the control cheese. Consumer acceptance results showed that microencapsulation failed to mask iron taste and color in the samples, a common problem when fortifying foods with iron. Iron salts tend to give metallic taste and brown tint when incorporated into food products. Zhang and Mahoney $(1989,1990)$, Prom-u-thai et al. (2009), and Kiskini et al. (2012) reported metallic flavors and color changes when fortifying foods with non-microencapsulated iron compounds. When utilizing microencapsulated ferrous sulfate to fortify pasteurized milk, significant negative sensory changes were also attributed to iron, particularly off color and flavors (Nkhata, 2012).

Table 5. Sensory evaluation of Cheddar cheese using a consumer acceptance panel $(\mathrm{n}=101)^{1}$

\begin{tabular}{lccc}
\hline Attribute & Control & LMFS & SMFS \\
\hline Appearance & $7.23^{\mathrm{a}}$ & $6.59^{\mathrm{b}}$ & $6.59^{\mathrm{b}}$ \\
Texture & $7.26^{\mathrm{a}}$ & $6.20^{\mathrm{b}}$ & $6.17^{\mathrm{b}}$ \\
Flavor & $7.30^{\mathrm{a}}$ & $3.68^{\mathrm{c}}$ & $4.47^{\mathrm{b}}$ \\
Overall acceptability & $7.32^{\mathrm{a}}$ & $3.94^{\mathrm{c}}$ & $4.58^{\mathrm{b}}$ \\
\hline
\end{tabular}

${ }^{\mathrm{a}-\mathrm{c}}$ Means within a row with different superscripts are significantly different $(P<0.05) ; \mathrm{n}=101$.

${ }^{1}$ LMFS $=$ large microencapsulated ferrous sulfate $(0.95 \mathrm{~g} / \mathrm{kg} ; 700$ $1,000 \mu \mathrm{m})$, SMFS $=$ small microencapsulated ferrous sulfate $(1.78 \mathrm{~g} /$ $\mathrm{kg} ; 220-420 \mu \mathrm{m})$. Evaluated on a scale $1-9$, where $9=$ like very much, $5=$ neither like nor dislike, $1=$ dislike extremely.
The success of fortification depends greatly on fortificant-food matrix interactions and possible sensory changes. Microencapsulated iron salts are a promising technology in dairy products, but it is hard to predict how microencapsulated compounds will work in a particular product. Cheddar cheese fortified with microencapsulated ferrous sulfate (at the selected dose) produced significant sensory differences affecting product acceptability, but sensory attributes may be more acceptable at lower doses.

It is important to note that, when comparing iron treatments, LMFS- and SMFS-fortified cheeses were scored differently for flavor and overall acceptability, yet SMFS-fortified cheeses were scored significantly higher than LMFS-fortified cheeses. During sensory evaluation, panelists were asked to provide comments about the samples. The control received mostly positive and neutral comments and LMFS-fortified cheeses received many negative comments, such as "very metallic flavors" or "bad taste." The SMFS-fortified cheeses received a mixed of positive and negative, as some panelists disliked this sample but others enjoyed it. Decreasing particle size for microencapsulated ferrous sulfate, from 1,000 to 700 or 422 to $220 \mu \mathrm{m}$, produced better results for flavor and overall acceptability in Cheddar cheese; likewise, iron's distinct color and flavor were better masked when using a smaller microencapsulated iron particle size.

To have a more complete sensory understanding of the iron-fortified Cheddar cheese, during sensory evaluation panelists were asked to describe texture and flavor attributes from a given list (Tables 6 and 7). For texture, half of the panelists $(\sim 50 \%)$ agreed that all samples had firm texture. For flavor, the control was described as buttery and salty by $\sim 50 \%$ of the panelists. For LMFS and SMFS samples, metallic flavors were perceived by more than $30 \%$ of the panelists. Moldy flavor was selected by $\sim 20 \%$ of the panelists for the iron treatments. Metallic and moldy flavors were very low for the control $(<5 \%)$. Vinegary flavor doubled for the iron treatments, from $7.9 \%$ in the control to $19.8 \%$ for LMFS-fortified cheese and $16.8 \%$ for SMFS-fortified cheese. However, we must point out this is an untrained panel, and thus the comments should be interpreted and used with caution. In summary, texture and flavor attribute descriptions agree with the fact that iron treatments scored significantly lower than the control because of iron's unique flavor and color.

\section{CONCLUSIONS}

Fortification of Cheddar cheese with microencapsulated ferrous sulfate produced no changes in fat, protein, ash, moisture, calcium, magnesium, and zinc content. 
Table 6. Texture attributes described by consumer acceptance panel $(\mathrm{n}=101)$ during sensory evaluation of Cheddar cheese fortified with microencapsulated ferrous sulfate ${ }^{1}$

\begin{tabular}{lccc}
\hline Attribute & Control, $\%$ & LMFS, $\%$ & SMFS, $\%$ \\
\hline Firm & 68 & 48 & 54 \\
Soft & 35 & 41 & 29 \\
Very hard & 5 & 5 & 5 \\
Grainy & 7 & 7 & 6 \\
Rubbery & 32 & 26 & 35 \\
Crumbly & 26 & 26 & 25 \\
Runny & 1 & 2 & 1 \\
Dry & 13 & 18 & 26 \\
Chewy & 35 & 27 & 26 \\
None & 0 & 1 & 1 \\
\hline
\end{tabular}

${ }^{1}$ LMFS $=$ large microencapsulated ferrous sulfate $(0.95 \mathrm{~g} / \mathrm{kg} ; 700-$ $1,000 \mu \mathrm{m})$, SMFS $=$ small microencapsulated ferrous sulfate $(1.78 \mathrm{~g} /$ $\mathrm{kg} ; 220-420 \mu \mathrm{m})$.

Microencapsulated ferrous sulfate (LMFS and SMFS) were successfully retained in Cheddar cheese. Based on iron content and percent recoveries, SMFS was better incorporated in Cheddar cheese. Regardless of the particle size, microencapsulated iron $\left(\mathrm{Fe}^{2+}\right)$ addition did not alter the divalent cation levels in the cheese. Iron fortification did not enhance lipid oxidation; however, consumer sensory panel results demonstrated that iron fortification negatively affected Cheddar cheese sensory attributes. Iron-fortified cheeses consistently scored lower in appearance, texture, flavor, and overall acceptability. The SMFS-fortified cheeses overall scored higher in acceptability than the LMFS-fortified Cheddar by the consumer panel, indicating the potential of reducing particle size for improving sensory changes caused by iron. Although, microencapsulated ferrous sulfate caused no major chemical changes in Cheddar cheese, the selected fortification dose (30\% Fe RDA, 4.5 $\mathrm{mg}$ of $\mathrm{Fe} / 28 \mathrm{~g}$ ) failed to produce acceptable sensory results. However, the results in this study are significant

Table 7. Flavor attributes described by consumer acceptance panel $(\mathrm{n}=101)$ during sensory evaluation of Cheddar cheese fortified with microencapsulated ferrous sulfate ${ }^{1}$

\begin{tabular}{lccc}
\hline Attribute & Control, $\%$ & LMFS, $\%$ & SMFS, $\%$ \\
\hline Sour-acidic & 21.8 & 29.7 & 25.7 \\
Vinegary & 7.9 & 19.8 & 16.8 \\
Greasy & 15.8 & 15.8 & 14.9 \\
Sweet & 13.9 & 5 & 10.9 \\
Metallic & 3 & 38.6 & 34.7 \\
Buttery & 64.4 & 21.8 & 33.7 \\
Salty & 47.5 & 31.7 & 27.7 \\
Moldy & 4 & 23.8 & 19.8 \\
Spicy & 0 & 1 & 0 \\
Other & 7.9 & 12.9 & 14.9 \\
None & 5.9 & 3 & 1 \\
\hline
\end{tabular}

${ }^{1}$ LMFS = large microencapsulated ferrous sulfate $(0.95 \mathrm{~g} / \mathrm{kg} ; 700$ $1,000 \mu \mathrm{m})$, SMFS $=$ small microencapsulated ferrous sulfate $(1.78 \mathrm{~g} /$ $\mathrm{kg} ; 220-420 \mu \mathrm{m})$. in that they show the significance of microencapsulation particle size in improving retention and sensory attributes in Cheddar cheese. This may be an effective way to enhance nutritional value by iron fortification with only minimal increase in the cost of the cheese. Future research should focus on fortificant levels as well as particle size.

\section{ACKNOWLEDGMENTS}

Funding support by USDA-National Institute of Food and Agriculture (Washington, DC) project \#MICL02496 is acknowledged. The authors express gratitude to the MSU Dairy Plant for helping with the Cheddar cheese manufacturing; to Wei Li and Jane Link (Michigan State University) for assisting with the atomic absorption spectroscopy methodology; and to Janice B. Harte (Michigan State University) for coordinating sensory evaluation.

\section{REFERENCES}

Allen, L., B. de Benoist, O. Dary, and R. Hurrell. 2006. Guidelines on food fortification with micronutrients. Part I, Part II and Part III. WHO Press, World Health Organization. Geneva, Switzerland. Accessed Apr. 21, 2015. http://www.who.int/nutrition/ publications/micronutrients/9241594012/en/.

AOAC International. 2000. Official Methods of Analysis. 17th ed. AOAC International, Arlington, VA.

Bailey, R. L., J. West, P. Keith, and R. E. Black. 2015. The epidemiology of global micronutrient deficiencies. Ann. Nutr. Metab. 66(Suppl 2):22-33. https://doi.org/10.1159/000371618.

Boccio, J. R., M. Zubillaga, R. Caro, C. Gotelli, M. Gotelli, and R. Weill. 1997. A New procedure to fortify milk and dairy products with high-bioavailable ferrous sulfate. Nutr. Rev. 55:240-246. https://doi.org/10.1111/j.1753-4887.1997.tb01611.x.

Cherayil, B. J. 2010. Iron and immunity: Immunological consequences of iron deficiency and overload. Arch. Immunol. Ther. Exp. (Warsz.) 58:407-415. https://doi.org/10.1007/s00005-010-0095-9.

Dubey, R., T. Shami, and K. Rao. 2009. Microencapsulation technology and applications. Def. Sci. J. 59:82-95. https://doi.org/10 $.14429 /$ dsj. 59.1489

Fiedler, J. L., and B. Macdonald. 2009. A strategic approach to the unfinished fortification agenda: Feasibility, costs, and cost-effectiveness analysis of fortification programs in 48 countries. Food Nutr. Bull. 30:283

Flyn, A., and K. Cashman. 1997. Nutritional aspects of minerals in bovine and human milks. Pages 269-274 in Advanced Dairy Chemistry. Vol 3. 2nd ed. P. F. Fox, ed. Chapman \& Hall, London, UK.

Frankel, E. 2014. Photooxidation of unsaturated fats. Pages 51-66 in Lipid Oxidation. 2nd ed. E. Frankel, ed. Woodland Publishing. Cambridge, UK.

Fulgoni, V. E., L. Victor, D. R. Keast, R. L. Bailey, and J. Dwyer. 2011. Foods, fortificants, and supplements: Where do Americans get their nutrients? J. Nutr. 141:1847-1854. https://doi.org/10 $.3945 /$ jn.111.142257.

Georgieff, M. K. 2011. Long-term brain and behavioral consequences of early iron deficiency. Nutr. Rev. 69:S43-48. https://doi.org/10 .1111/j.1753-4887.2011.00432.x.

Gonzalez-Martin, I., J. M. Hernandez-Hierro, I. Revilla, A. VivarQuintana, I. Lobos-Ortega, and C. Gonzalez-Perez. 2009. Changes in the mineral content in cheeses of different compositions during 6 months of ripening. Czech J. Food Sci. 27:114-118. 
Gulbas, S. Y., and I. Saldami. 2005. The effect of selenium and zinc fortification on the quality of Turkish of white cheese. Int. J. Food Sci. Nutr. 56:141-146.

Horton, S., H. Alderman, and J. Rivera. 2008. Hunger and malnutrition. Copenhagen consensus: Malnutrition and Hunger. Pages 305-333 in Global Crises, Global Solutions. B. Lomborg, ed. Cambridge University Press, Cambridge, UK.

IDFA. 2016. Cheese production. International Dairy Foods Association. Accessed on May 2, 2016. http://www.idfa.org/news-views/ media-kits/cheese/cheese-production.

Kahraman, O., and Z. Ustunol. 2012. Effect of zinc fortification on Cheddar cheese quality. J. Dairy Sci. 95:2840-2847. https://doi .org/10.3168/jds.2011-4945.

Keast, D. R., E. Fulgoni, N. Victor, T. A. Nicklas, and C. E. O'Neil. 2013. Food sources of energy and nutrients among children in the United States: National health and nutrition examination survey 2003-2006. Nutrients 5:283-301. https://doi.org/10.3390/ nu5010283.

Kiskini, A., M. Kapsokefalou, S. Yanniotis, and I. Mandala. 2012. Effect of iron fortification on physical and sensory quality of glutenfree bread. Food Bioprocess Technol. 5:385-390. https://doi.org/ 10.1007/s11947-011-0651-2.

Kwak, H. S., K. M. Yang, and J. Ahn. 2003. Microencapsulated iron fortification and flavor development in cheddar cheese. Asian-Australas. J. Anim. Sci. 16:1205-1211.

Malpeli, A., M. G. Ferrari, A. Varea, M. Falivene, G. Etchegoyen, M. Vojkovic, and H. F. Gonzalez. 2013. Short-term evaluation of the impact of a fortified food aid program on the micronutrient nutritional status of Argentinian pregnant women. Biol. Trace Elem. Res. 155:176-183. https://doi.org/10.1007/s12011-013-9780-y.

Mehta, B. M., K. D. Aparnathi, and V. B. Darji. 2015. Comparison of different methods of monitoring the secondary stage of oxidation of ghee. Int. J. Dairy Technol. 68:589-594. https://doi.org/10 1111/1471-0307.12232.

Motzok, I., M. D. Pennell, M. I. Davies, and H. U. Ross. 1975. Effect of particle size on the bioavailability of reduced iron. J. Assoc. Off. Anal. Chem. 58:99-103.

Nkhata, S. 2013. Iron fortification of yogurt and pasteurized milk. Unpublished Master's Thesis. College of Agriculture and Natural Resources, Department of Food Science and Human Nutrition. Michigan State University, East Lansing.

On-Nom, N., A. S. Grandison, and M. J. Lewis. 2010. Measurement of ionic calcium, $\mathrm{pH}$, and soluble divalent cations in milk at high temperature. J. Dairy Sci. 93:515-523. https://doi.org/10.3168/ jds.2009-2634.

Patiño, E., E. Faisal, J. Cedres, F. Mendez, and C. Guanziroli-Stefani. 2005. Contenido mineral de leche de búfalas (Bubalus bubalis) en Corrientes, Argentina. Rev. Vet. 16:40-42.

Peres, J., S. Bouhallab, F. Bureau, J. Maubois, P. Arhan, and D. Bougle. 1999. Reduction of iron/zinc interactions using metal bound to the caseinophosphopeptide $1-25$ of $\beta$-casein. Nutr. Res. 19:1655-1663. https://doi.org/10.1016/S0271-5317(99)00121-9.

Philippe, M., Y. Le Graët, and F. Gaucheron. 2005. The effects of different cations on the physicochemical characteristics of casein micelles. Food Chem. 90:673-683. https://doi.org/10.1016/j .foodchem.2004.06.001.

Prom-u-thai, C., B. Rerkasem, S. Fukai, and L. Huang. 2009. Iron fortification and parboiled rice quality: Appearance, cooking quality and sensory attributes. J. Sci. Food Agric. 89:2565-2571. https:/ doi.org/10.1002/jsfa.3753.

Raouche, S., M. Dobenesque, A. Bot, A. Lagaude, and S. Marchesseau. 2009. Casein micelles as a vehicle for iron fortification of foods. Eur. Food Res. Technol. 229:929-935. https://doi.org/10 .1007/s00217-009-1130-0.

Rice, W. H., and D. J. McMahon. 1998. Chemical, physical, and sensory characteristics of mozzarella cheese fortified using proteinchelated iron or ferric chloride. J. Dairy Sci. 81:318-326.

Sadava, D., C. H. Heller, G. H. Orians, W. K. Purves, and D. M. Hillis 2008. Life: The Science of Biology. 8th ed. W.H. Freeman and Company, Gordonsville, VA.

Sugiarto, M., A. Ye, M. W. Taylor, and H. Singh. 2010. Milk proteiniron complexes: Inhibition of lipid oxidation in an emulsion. Dairy Sci. Technol. 90:87-98.

USDA National Nutrient Database for Standard Reference. 2016. Milk, cheddar cheese and Mozzarella. Accessed April 25, 2016. https://ndb.nal.usda.gov/.

Vasudevan, P., V. Padmavathy, and S. C. Dhingra. 2002. Biosorption of monovalent and divalent ions on baker's yeast. Bioresour. Technol. 82:285-289. https://doi.org/10.1016/S0960-8524(01)00181-X.

Wegmüller, R., M. B. Zimmermann, D. Moretti, W. Langhans, and R. F. Hurrrell. 2004. Particle size reduction and encapsulation affect the bioavailability of ferric pyrophosphate in rats. J. Nutr. 134:3301-3304.

West, D. W. 1986. Structure and diction of the phosphorylated residues of casein. J. Dairy Res. 53:333-352.

WHO. 2016. Iron deficiency anemia. Micronutrient deficiencies. World Health Organization. Accessed March 2, 2016. http://www.who .int/nutrition/topics/ida/en/.

Zhang, D., and A.W. Mahoney. 1989. Effect of iron fortification on quality of cheddar cheese. J. Dairy Sci. 72:322-332. https://doi .org/10.3168/jds.S0022-0302(89)79113-X.

Zhang, D., and A.W. Mahoney. 1990. Effect of iron fortification on quality of cheddar cheese. 2. effects of aging and fluorescent light on pilot scale cheeses. J. Dairy Sci. 73:2252-2258. /https://doi .org/10.3168/jds.S0022-0302(90)78905-9.

Zhang, D., and A. W. Mahoney. 1991. Iron fortification of process cheddar cheese. J. Dairy Sci. 74:353-358. 